\title{
ЛИНГВИСТИКА
}

\section{E. А. Дадуева \\ СЕМАНТИЧЕСКИЕ ОСОБЕННОСТИ КОНСТРУКЦИЙ С ГЛАГОЛАМИ ДВОЙНОЙ КАУЗАЦИИ В БУРЯТСКОМ ЯЗЫКЕ}

Каузативность - функционально-семантическая категория, находящая реализацию на разных уровнях языковой системы. Каузативация является здесь одной из самых продуктивных дериваций. Каузативные маркеры могут присоединяться как к непроизводным основам, так и к производным. В статье показано, что довольно часто в бурятском языке встречается двойное маркирование каузативных глаголов - двойная каузация, которая свойственна агглютинативным языкам. Основной целью данной статьи является исследование семантических особенностей явления двойной каузации в бурятском языке. В задачи входит рассмотрение формальных признаков глаголов с двойной каузацией, анализ их семантических и функциональных особенностей. Так, исследование показало, что в образовании глаголов двойной каузации в бурятском языке участвуют продуктивные суффиксы -уул и -лга. Другие аффиксы в образовании второй степени каузации не участвуют. Также выявлено, что большее распространение здесь имеет порядок присоединения аффиксов, при котором не дублируются одни и те же аффиксы, а присоединяются новые, при этом непродуктивные суффиксы всегда предшествуют продуктивным. В семантическом плане двойная каузация в бурятском языке указывает на многочисленность отдельных участников каузативной ситуации, которая предполагает выражение значения дистантной каузации. Также двойная каузация служит для выражения значения пермиссивной каузации. Двойное каузирование способно выражать значение интенсивности или многократности каузативного действия, а также значение поэтапного каузирования. Двойная каузация в бурятском языке может быть также признаком избыточного маркирования, простого дублирования. В бурятском языке каузативные суффиксы могут выступать в страдательном значении и утрачивать значение каузативности, но нами отмечен факт того, что такие неканонические случаи использования каузативных аффиксов также допускают двойную каузацию, которая представляется избыточной. В работе также уделяется внимание вопросу о двойной каузации лексических каузативов, при которой каузативации подвергаются немаркированные каузативные глаголы. Двойная каузация в этом случае может служить средством выражения дистантной каузации.

Ключевые слова: двойная каузация, каузативный глагол, каузаџия, лексический каузатив, морфологический каузатив, каузативные аффиксы, дистантная каузаиия.

Каузативность как функционально-семантическая категория представляет большой интерес для исследователей различных языков мира. Актуальность исследований в этой области обусловлена тем, что каузативность, несмотря на огромный интерес, продолжает оставаться достаточно спорным явлением, в котором множество вопросов требует разъяснений и уточнений. В этой связи ее изучение на материале разных языков, безусловно, поможет становлению теории каузативности. В бурятском же языкознании данная категория только начинает исследоваться (Дадуева, 2011). Изучение каузативности здесь на данном этапе имеет множество неразрешенных вопросов. Так, изучаемый нами бурятский язык обладает богатыми морфологическими средствами выражения (Дадуева, 2014). При анализе словарного материала в бурятском языке обнаруживается следующий факт: в морфемный состав каузативных глаголов может входить более одного каузативного суффикса. Возникает вопрос: для чего здесь используется двойная суффиксация, какую семантику она передает?

Такое явление в языкознании называют двойной каузацией (Перехвальская, 2017, Недялков, 1969, Comrie, 1981 и др.), the second causative (Kulikov, 1993). Как отмечают исследователи, двойной каузатив допустим в различных языках (Недялков, 1969: 27). Явление двойной 
каузации рассматривалось в той или степени в киргизском языке, где используется термин «вторичные каузативные глаголы» (Абдиев, 2009), в башкирском языке (Перехвальская, 2017), в калмыцком языке (Сай, 2009). В русском языке распространен синтаксический тип выражения двойного каузатива, например: Врач попросил нас заставить детей пить лекарство. Двойную каузацию называют также каузацией каузации (Kulikov, 1993; Сай, 2009). В бурятском языке двойная каузация специально не исследовалась, что обуславливает актуальность и новизну изучения данной проблемы. Л. И. Куликов только лишь подтверждал существование двойного и даже тройного каузатива в монгольском и бурятском языках, однако дальнейшего развития тема не получила (Kulikov, 1993: 124).

Основной целью данной статьи является исследование явления двойной каузации в бурятском языке. В задачи статьи входит рассмотрение формальных признаков глаголов с двойной каузацией, анализ их семантических и функциональных особенностей.

При первичной каузативации в бурятском языке используются как продуктивные, так и непродуктивные суффиксы. К непродуктивным суффиксам мы относим такие каузативные суффиксы, как га (-го, -гэ), -гаa (-гээ, -гоо, -гөө), -ха (-хэ, -хо), -хаa (-хээ, -хоо), -аa (-ээ, -оо, $-\theta \theta)$, а к продуктивным - -уул (-юул, -Үүл), -лга (-лгэ, -лго). При вторичной каузативации глаголов используются только продуктивные суффиксы, что означает предшествование непродуктивных суффиксов продуктивным. Например: гар-г-yул-ха 'заставить вынести от гар-га-ха 'вынести`, hyp-г-уул-ха `позволять, заставлять кого-либо учиться у кого-либо' от hyp-га-ха 'учить', гэмт-ээ-лгэ-хэ 'заставлять повреждать' от гэмт-ээ-хэ 'повреждать, наносить повреждение', сад-хаa-лга-ха `позволять насытиться' от сад-хаa-ха 'насыщать', haл-гаa-лга-ха 'заставлять разделять, разнимать` от haл-гаa-xa `разделять, разнимать', хал-аa-лга-ха `заставлять греть`от хал-aa-xa `нагревать`и т.д.

При двойной каузации в различных языках наблюдается 2 случая присоединения аффиксов: 1) вторичное присоединение одного и того же аффикса; 2) присоединение нового аффикса (Недялков, 1969: 27). В бурятском языке первый способ не получил особого распространения. Так, продуктивный суффикс -лга и все непродуктивные суффиксы здесь не могут быть присоединены дважды. На наш взгляд, в бурятском языке вторично присоединяться может только продуктивный суффикс -уул (-юул, -ҮYл). Например: хэлс-Үүл-хэ 'быть предметом разговоров` $\rightarrow$ хэлс-ҮYл-ҮYл-хэ `позволять о себе говорить ', хар-уул-ха `показывать ' $\rightarrow$ хар-уулл-уул-ха `заставлять показывать ' и т. д. Подобные примеры не вызывают у информантов опровержений, хотя в словарях такие варианты встречаются очень редко, например: орш-уул-ха `переводить $\rightarrow$ opu-yул-уулл-ха `заставлять переводить'. Но стоит заметить, что такой способ образования вторичных каузативных глаголов мало распространен, но вполне возможен в бурятском языке. Второй из указанных выше способов присоединения аффиксов, при котором присоединяется новый каузативный аффикс, без сомнения, является продуктивным в исследуемом языке. Ср.:

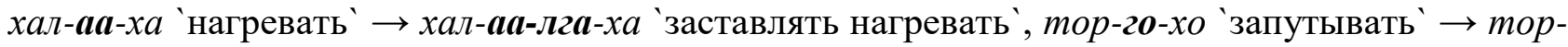
2-yул-ха `заставлять запутывать` и т. д.

Интересным представляется то, что некоторые источники считают, что в бурятском языке после суффикса -уул не может быть применен какой-либо второй каузативный суффикс, поэтому значение опосредованной каузации передается описательным путем (Недялков, 1969: 28; Грамматика бурятского языка, 1962: 208).По нашему мнению, в бурятском языке после суффикса -уул можно присоединить суффиксы -лга и -уул, о котором мы упоминали выше. Что касается суффикса -лга, он легко присоединяется к суффиксу -уул. В речи подобные примеры используются довольно часто и фиксируются в словарях. Например: яб-уул-ха `посылать ' $\rightarrow$

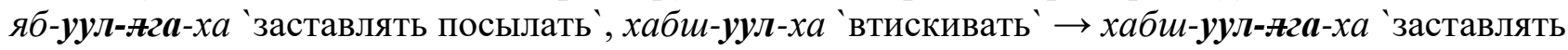
втиснуться', сугл-уул-лга-ха `заставлять собирать`от сугл-уул-ха 'собирать`.

Г. Д. Санжеев, касательно побудительного залога, указывал, что большая часть активных и пассивных непереходных глаголов в монгольском языке не может присоединять более одного побудительного суффикса (Санжеев, 1963: 29). В бурятском языке данное утверждение 
касается только ограниченного круга глаголов, по нашим наблюдениям, двойной каузации могут быть подвергнуты и непереходные, и переходные глаголы. Однако такие глаголы, как ерэхэ, ошохо, унтаха, хэбтэхэ и т.д., действительно, образуют только первую степень каузации. Ср.: ерэ-хэ 'приходить 'ер-үүл-хэ `заставлять приходить, вызывать', ошо-хо `идти` - ош-уул$x a$ 'заставлять идти, посылать` и т. д. Но указанные Г. Д. Санжеевым, как не имеющие возможность присоединения второго аффикса, монгольские глаголы суyx 'сидеть' - cyy-лга- $x$; явах 'идти' - яв-уул-ах в бурятском языке допускают двойную каузацию. Ср. бурятские эквиваленты: hyy-ха 'сидеть ' $\rightarrow$ hyy-лга-ха `посадить ' $\rightarrow$ hyy-лг-уул-ха `заставлять посадить', яба$x a$ `идти` $\rightarrow$ яб-уулл-ха `отправить ' $\rightarrow$ яб-уун-лга-ха `заставлять отправить` и т.д.

Таким образом, в образовании глаголов двойной каузации в бурятском языке участвуют продуктивные суффиксы -уул и -лга. Другие каузативные аффиксы в образовании второй степени каузации не используются. Здесь имеет большую продуктивность такой порядок присоединения аффиксов, при котором не дублируются одни и те же аффиксы, а присоединяются новые. При этом непродуктивные суффиксы всегда предшествуют продуктивным.

Далее рассмотрим, что нового в семантику каузативного глагола добавляет двойная каузация в бурятском языке, для выражения каких значений она предназначена?

Выделим основные семантические особенности конструкций с глаголами двойной каузации. Двойная каузация, в первую очередь, указывает в бурятском языке на многочисленность участников каузативной ситуации. Семантика двойной каузации заключается в том, что каузатор воздействует на некий каузируемый субъект, чтобы тот, в свою очередь, воздействовал на третий субъект, который и оказывается реальным исполнителем действия, выраженного каузативным глаголом. В такой каузативной ситуации число участников достигает как минимум трех: каузатор, каузируемый субъект или объект и непосредственный исполнитель действия. Например:

\begin{tabular}{|c|c|c|c|}
\hline $\begin{array}{l}\text { Бu } \\
\text { Я-PRON }\end{array}$ & $\begin{array}{l}\text { аша-яа } \\
\text { внук-АСС }\end{array}$ & $\begin{array}{l}\text { шам-да } \\
\text { ты-DAT }\end{array}$ & $\begin{array}{l}\text { һур-г-уул-хаб! } \\
\text { обучать-CAUS-CAUS-FUT }\end{array}$ \\
\hline
\end{tabular}

Каузатором в данной ситуации выступает говорящий, каузируемым субъектом является внук, непосредственный исполнитель действия - третий субъект, который и будет выполнять каузируемое действие - обучать. В каузативной ситуации с простым каузативом наблюдается всего два участника события - каузатор и каузируемый субъект. Ср.:

\begin{tabular}{|c|c|c|}
\hline $\begin{array}{l}\text { Би } \\
\text { Я-PRON }\end{array}$ & $\begin{array}{l}\text { аша-яа } \\
\text { внук-АСС }\end{array}$ & $\begin{array}{l}\text { hур-га-хаб. } \\
\text { обучать-CAUS-FUT }\end{array}$ \\
\hline
\end{tabular}

Такое значение многочисленности участников каузативной ситуации закономерно связано с тем, что одной из функций двойного каузатива является выражение значения дистантной каузации. Дистантная каузация представляется типологически закономерной при двойном каузативе, что связано с тем, что двойное каузирование добавляет посредника в исполнении определенного действия, т.е. возникает значение опосредованного действия. Masayoshi Шибатани, говоря о контактной и дистантной каузации, считал, что в языках должны быть дополнительные средства для выражения дистантной каузации (Shibatani, 2002). Именно таким средством выражения дистантной каузации в бурятском языке является двойная каузация. Например:
3. Tэрэ
самса-яа
һамган-даа
OH-PRON-NOM
одежда-ACC жена-DAT
хат-аа-лга-ба
'Он заставил жену посушить его одежду’.
сушить-CAUS-CAUS-PST 
В подобных конструкциях с двойным каузативом в бурятском языке чаще всего встречается дистантная каузация, при которой наблюдаются опосредованные отношения между неким каузирующим субъектом (Тэрэ 'он') и каузируемым состоянием (хата-ха 'сохнуть'). Посредником, который и выполнит каузируемое действие, в данном случае является еще один участник ситуации (һамган 'жена').

Далее заметим, что значение многочисленности участников каузативной ситуации предполагает, что двойная каузация реализует значение волевого воздействия на каузируемых участников. Значение волевого воздействия здесь может быть, как фактитивным, так и пермиссивным в зависимости от каузативной ситуации. Фактитивное и пермиссивное значение зависит от характера воздействия каузатора. Если действие инициируется самим каузатором, то глагол выражает фактитивную каузацию. Если каузатор лишь позволяет или не препятствует объекту совершить действие, то глагол выражает значение пермиссивной каузации. В основном в словарях фиксируется фактитивное значение, например: бусал-г-уул-ха 'велеть вскипятить 'от бусал-га-ха 'кипятить', бүт-ээ-лгэ-хэ `велеть завершить 'от бүm-ээ-хэ 'завершить`, буса-лг-уул-ха `велеть вскипятить` от буса-лга-ха `кипятить и т. д.

Пермиссивное значение фиксируется очень редко, хотя двойная каузация в бурятском языке довольно часто может выражать пермиссивную каузацию. По нашему мнению, еще одной из функций двойной каузации в бурятском языке является реализация значения именно пермиссивной каузации. Например:

4. Манай тоодээ тэдэ-эниие хайрлажа гэр-тээ хон-уул-лга-даг

Наша бабушка они-ACC жалеть дом-DAT ночевать-CAUS-CAUS-PRS

'Наша бабушка, жалея их, позволяет им ночевать у себя дома'.

Глагол хон-уул-ғга-ха содержит два каузативных аффикса -уул $и$-лга и обозначает действие, позволенное сделать объекту, т.е. реализует пермиссивное значение.

В пермиссивных конструкциях встречаются ситуации, в которых субъект не контролирует или допускает наступление «неприятного» действия. Например:

$\begin{array}{lll}\text { Tэрэ } & \text { мях-аa } & \text { Үж-ээ-лгэ-бэ } \\ \text { Oн-PRON } & \text { мясо-ACC } & \text { гнить-CAUS-CAUS-PST }\end{array}$

Глагол үж-ээ-лгэ-хэ содержит два каузативных аффикса -ээ и -лгэ. Ср.: үжэ-хэ 'гнить' $\rightarrow$ үж-ээ-Хэ `гноить, портить ' $\rightarrow$ үж-ээ-лгэ-хэ `позволять портиться, сгнить . Использование второго каузативного суффикса придает глаголу пермиссивное значение. Глагол в данном контексте выражает действие, нежелательное, неприятное для субъекта.

Также отметим, что двойная каузация способна выражать значение интенсивности или многократности каузативного действия, что тоже считается типологически закономерным (Куликов, 1993). В бурятском языке часто встречается данное значение при двойной каузации. Например: Бус-аa-лга-ха `добиваться возвращения` от бус-аa-ха `возвращать`. Сравним два примера:

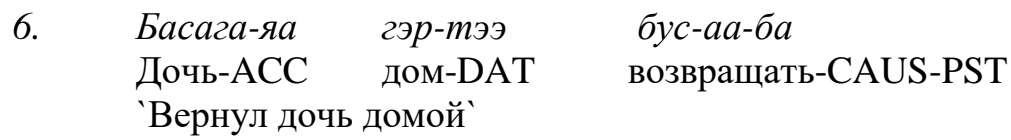

7. Басагаяа гэр-тээ бус-аа-лга-ба

Дочь-ACC дом-DAT возвращать-CAUS-CAUS-PST

'Возвратил (очень долго и настойчиво возвращал) дочь домой’. 
Как мы видим, в примере (7) использование двойной каузации меняет семантическую структуру предложения.

Рассмотрим еще пример:

$\begin{array}{llll}\text { 8. } & \text { Харгил ... } & \text { хутаг-ьеень } & \text { алд-уул-жга-ба. } \\ \text { Харгил ... } & \text { нож-АСС } & \text { уронить-CAUS-CAUS-PST } \\ \text { 'Харгил заставил его уронить нож` (Сокровенное сказание монголов). }\end{array}$

В данном примере глагол алд-уул-дга-ха `заставить уронить, потерять, выхватить , образованный от каузативного глагола алд-уул-ха 'заставить уронить ’, содержит два каузативных суффикса, при этом суффикс -уул предшествует суффиксу -лга. На наш взгляд, глагол aлд-уул-лга-хa не добавляет нового значения к производящему глаголу, а только лишь способствует усилению, интенсификации каузативного значения.

Интересно также то, что в бурятском языке двойная каузация может обозначать поэтапное каузирование. Например: ниидэ-хэ `лететь' $\rightarrow$ ниид-хэ-хэ `снаряжать в полет $\rightarrow$ ниид- $x$ үүл-хэ 'отправлять в полет`.

Двойная и даже тройная каузация может быть и признаком избыточного маркирования, когда второй каузативный суффикс не добавляет нового актанта в актантную структуру каузативной конструкции (Куликов, 1993). Такое явление можно назвать простым дублированием каузативного значения, при котором не изменяется ни количество участников, ни семантика.

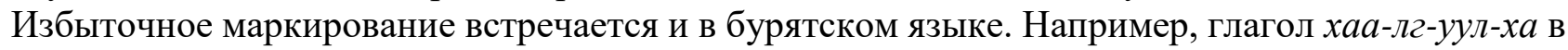
примере (9) не добавляет нового участника и не модифицирует семантику каузативной ситуации. Оба примера реализуют одинаковое значение. Ср.:

9. Сонхоо $\quad$ басаган-даa
Окно-АСС $\quad$ дочь-лг-уул-ба
'Заставил дочь закрыть окно
10. Сонхоо басаган-даа хаа-лга-ба
Окно-ACC дочь-DAT закрыть-CAUS-PST
'Заставил дочь закрыть окно'.

В бурятском языке также существуют примеры неканонического использования каузативных маркеров, при котором каузативные суффиксы могут выступать в страдательном значении и утрачивать значение каузативности. Интересным является тот факт, что такие неканонические примеры также допускают двойную каузацию, которая здесь тоже представляется избыточной. Например:

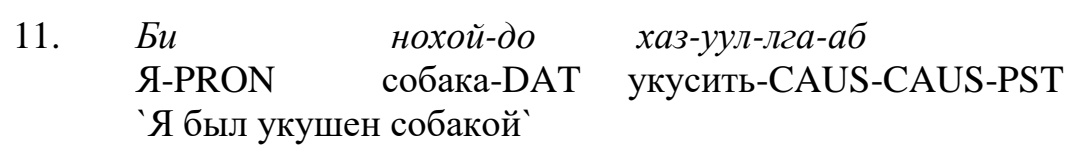

Также стоит сказать о семантических особенностях глаголов с тройной каузацией. Тройная каузация в бурятском языке формально возможна. Например: гэдэ-хэ `таять $\rightarrow$ гэд-хээ- хэ 'оттаивать $\rightarrow$ гэд-хээ-лгэ-хэ 'заставлять, позволять оттаивать ' $\rightarrow$ гэд-хээ-лг-ҮYл-хэ `заставлять оттаивать . Формально подобные тройные каузативы, конечно, могут иметь место, но в семантическом плане, на наш взгляд, являются избыточными. Хотя в некоторых случаях наблюдаются семантические различия двойного и тройного каузатива. Например: $x a m-a \boldsymbol{a}-x a$ 'сушить' $\rightarrow$ xam-aa-лга- $x a$ 'заставить сушить $\rightarrow$ xam-aa-лг-yул- $x a$ 'заставить высушить себя / свои вещи`. Здесь мы видим, что в тройном каузативе появляется новое значение - каузируемое действие направляется на самого каузатора опосредованно через третье лицо, каузатор как бы 
просит или заставляет выполнить определенное действие для себя, в своих интересах. Ср. также: $х а л-\boldsymbol{a a}-л г-y \boldsymbol{л}-x a$ 'просить или заставлять нагревать что-либо для себя', нос-оо-лг-уул$x a$ `просить зажечь для себя` и т.д.

Как мы уже говорили выше, к семантическим особенностям конструкций с глаголами двойной каузацией относится выражение значения волевого воздействия, которое всегда имеет значение дистантной каузации. В языкознании двойная каузация понимается в основном только как добавление второго каузативного аффикса к уже маркированному каузативному глаголу, т.е. каузативация морфологического каузатива. По нашему мнению, двойной каузацией можно считать и каузативацию, при которой каузативный аффикс добавляется к каузативному глаголу, не маркированному каузативным аффиксом. Это явление можно назвать каузативацией лексических каузативов. Такие каузативы также получают значение волевого воздействия. Смеем предположить, что данная каузативация получает распространение в языках, имеющих возможность двойной каузации морфологического каузатива, как в бурятском языке. Здесь возможна двойная каузация лексического каузатива. Например, от лексического каузатива ала-ха 'убить' образуется двойной каузатив ал-уул-ха 'велеть, позволить убить', маркированный суффиксом -уул. Также сравните: $x a a-x a$ `закрывать' $\rightarrow x a a-л г a-x a$ 'заставить закрывать ’, нээ-хэ 'открывать` $\rightarrow$ нээ-лгэ-хэ `заставить открывать ’, няаха `приклеивать $\rightarrow$ няа-лга-ха `заставить приклеивать и т.д. В данном случае продуктивными в образовании двойной каузации от лексического каузатива выступают продуктивные суффиксы -уул $u$-лга.

Сравним каузативные конструкции с парами глаголов:

\section{2.

$$
\begin{aligned}
& \text { Би магазин-аa } \\
& \text { Я магазин-АСС } \\
& \text { 'Я закрыл }
\end{aligned}
$$

\section{3.-. Tэд намайе \\ Они-PRON я-ACC магазин-ACC \\ магазинымм \\ хаа-лга-ба закрыть-CAUS-PST \\ 'Они заставили меня закрыть магазин'}

В примере (12) наблюдаем лексический каузатив $x a a-x a$, который выражает фактитивное значение контактной каузации, т. е. непосредственное физическое воздействие на каузируемый объект. Двойная каузация представлена в примере (13). Двойной каузатив хaа-лга-ха выражает фактитивное дистантное значение каузации, т.е. опосредованное волевое воздействие на каузируемый субъект.

Итак, двойная каузация в бурятском языке имеет большую словообразовательную продуктивность: практически от любого простого каузативного глагола можно образовать каузативный глагол второй и даже третьей степени. К формальным особенностям двойной каузации можно отнести то, что, во-первых, двойная каузация образуется только при помощи продуктивных суффиксов -уул и -лга. Во-вторых, здесь получает большее распространение порядок присоединения аффиксов, при котором не дублируются одни те же суффиксы, а присоединяются новые. Конструкции с глаголами двойной каузации в бурятском языке имеют свои семантические особенности. Чаще всего они обозначают многочисленность участников каузативной ситуации, которая предполагает выражение значения дистантной каузации. Все глаголы с двойным каузативным суффиксом выражают в бурятском языке семантику волевого воздействия. Такие конструкции здесь могут реализовывать как фактитивное значение каузации, так и пермиссивное. Также двойная каузация способна выражать значение интенсивности или многократности каузативного действия и значение поэтапного каузирования. Двойная и даже тройная каузация может быть и признаком избыточного маркирования. В бурятском языке нами зафиксированы случаи использования двойной аффиксации в конструкциях со 
страдательным некаузативным значением. Также мы считаем возможным выделение такого понятия, как двойная каузация лексических каузативов, при которой каузативации подвергаются немаркированные каузативные глаголы бурятского языка.

\section{Список литературы:}

Aбдиев T. Конструкции с каузативными глаголами в киргизском языке. - Бишкек, Изд-во Кыргызско-турецкого университета «Манас», 2009. - 114 с.

Грамматика бурятского языка. - М., 1962.

Дадуева E. A. Функционально-семантическая категория каузативности в русском и бурятском языках. -Улан-Удэ: Изд-во Бурятского госуниверситета, 2011. - 128 с.

Дадуева E. А. Каузативные афффиксы в бурятском языке // Вестник Бурятского государственного университета. Язык. Литература. Культура. - Улан-Удэ. - 2014. - № 1. - С. 4-8

Недялков В. П., Сильницкий Г. Г. Типология морфологического и лексического каузативов / В. П. Нелялков // Типология каузативных конструкций. - Л.: Наука, 1969. - 311 с.

Перехвальская $\boldsymbol{E}$. В. Каузативные конструкции в башкирском языке // Acta linguistica petropolitana. Труды института лингвистических исследований. - 2017. - Т. 13, № 1. - С. 231-254.

Сай С. С. Аргументная структура калмыцких каузативных конструкций // Acta Linguistica Petropolitana. Tруды института лингвистических исследований. - 2009. Т. 5, № 2. - С. 387-464.

Санжеев Г. Д. Сравнительная грамматика монгольских языков. Глагол / Г. Д. Санжеев. - М.: Изд-во Восточной литературы, 1963. - Т. 2. - 267 с.

Comrie, Bernard. Language Universals and Linguistic Typology. Oxford. 1981.

Kulikov, Leonid. The "second causative": a typological sketch. // Comrie, Polinsky (eds.). - 1993. - P. 121-154.

Shibatani M., Pardeshi P. The causative continuum // The grammar of causation and interpersonal manipulation / Masayoshi Shibatani (ed.). - Amsterdam; Philadelphia: John Benjamin, 2002. - P. 96.

Список источников:

Сокровенное сказание монголов. - Улан-Удэ, 1990.

Условные обозначения грамматических значений в глоссах:

ACC - винительный падеж; DAT - дательный падеж; NOM - номинатив, CAUS - каузативный; PRON - местоимение, PRS - настоящее время / PST - прошедшее время/ FUT - будущее время.

Дадуева Елена Александровна - кандидат филологических наук, доцент.

Бурятский институт инфокоммуникаций (филиал) Сибирского государственного университета телекоммуникаций и информатики в г. Улан-Удэ.

Ул. Ключевская, 64-69, Улан-Удэ, Россия, 670013.

E-mail: edadueva@yandex.ru

\section{E. A. Dadueva}

\section{SEMANTIC FEATURES OF CONSTRUCTIONS WITH VERBS OF DOUBLE CAUSATION IN THE BURYAT LANGUAGE}

Causativity is a functional-semantic category, which is implemented at different levels of the language system. Causative verbs in the Buryat language have morphological expression. Causation is one of the most productive derivations here. Causative markers can be attached to both non-derived bases and derivatives. Quite often in the Buryat language there is a double marking of causative verbs-double causation, which is characteristic of agglutinative languages. The main purpose of this article is to study the phenomenon of double causation in the Buryat language. The tasks include consideration of formal features of verbs with double causation, analysis of their semantic and functional features. Thus, it is 
show that productive suffixes -uul, -lga participate in the formation of double causation in the Buryat language. Other affixes do not participate in the formation of the second degree of causation. It is also revealed that the order of affixes addition is more widespread here, in which the same affixes are not duplicated, but new ones are added, while unproductive suffixes always precede productive ones. Double causation in the Buryat language indicates the large number of individual participants in the causative situation, which involves the expression of the value of distant causation, the expression of the value of permissive causation. Also, double causation is able to Express the value of intensity or multiplicity of causative action, the value of step-by-step causation. Double and even triple causation can also be a sign of excessive marking, simple duplication. In the Buryat language, causative suffixes can appear in the passive sense and lose the value of causation, but we note the fact that such examples also allow for double causation, which is also excessive. The paper also draws attention to the question of double causation of lexical causatives, in which the causative are not marked causative verbs.

Key words: double causation, causative verb, causation, lexical causative, morphological causative, causative affixes, distant causation.

\section{References:}

Abdiev $T$. Konstrukcii s kauzativnymi glagolami v kirgizskom yazyke [Constructions with causative verbs in Kyrgyz]. Bishkek, Publishing house of the Kyrgyz-Turkish University " Manas», 2009, - 114 p. (in Russian).

Grammatika buryatskogo yazyka [The Grammar of the Buryat language]. - Moscow, 1962. (in Russian).

Dadueva E. A. Funkcional'no-semanticheskaya kategoriya kauzativnosti v russkom i buryatskom yazykah. [Functionalsemantic category of causativity in Russian and Buryat languages]. Ulan-Ude: Buryat state University publishing house, 2011. - 128 p. (in Russian)

Dadueva E. A. Kauzativnye affiksy v buryatskom yazyke [Causative affixes in the Buryat language] // Bulletin of Buryat state University.- Ulan-Ude. - 2014. - № 1. - P. 4-8 (in Russian)

Nedyalkov V. P., Sil'nickij G. G. Tipologiya morfologicheskogo i leksicheskogo kauzativov [Typology of morphological and lexical causatives]. V. P. Nedyalkov. Typology of causative constructions. - Leningrad, Nauka, 1969 - 311 p. (in Russian).

Perekhval'skaya E. V. Kauzativnye konstrukcii v bashkirskom yazyke [Causative constructions in the Bashkir language] // Acta linguistica petropolitana. - 2017. - T. 13, № 1. - P. 231-254 (in Russian).

Saj S. S. Argumentnaya struktura kalmyckih kauzativnyh konstrukcij [The argument structure of the Kalmyk causative constructions ] // Acta linguistica petropolitana. - 2009. - T. 5. № 2. - C. 387-464 (in Russian).

Sanzheev G. D. Sravnitel'naya grammatika mongol'skih yazykov. Glagol [Comparative grammar of Mongolian languages. Verb]. - Moscow, 1963. - T. 2. - 267 p. (in Russian).

Comrie, Bernard. Language Universals and Linguistic Typology. - Oxford, 1981.

Kulikov L. The "second causative": a typological sketch. Comrie, Polinsky (eds.) - 1993. P. 121-154

Shibatani M., Pardeshi P. The causative continuum. The grammar of causation and interpersonal manipulation. Masayoshi Shibatani (ed.). - Amsterdam; Philadelphia: John Benjamin, 2002. - P. 96.

\section{Text sources:}

Sokrovennoe skazanie mongolov. - Ulan-Ude, 1990.

Dadueva Elena A. Candidate of Philology, associate professor

Buryat Institute of Infocommunications (branch) of the Siberian State University of Telecommunications and Informatics in Ulan-Ude.

Ul. Kliychevskay, 64-69, Ulan-Ude, Russia, 670013.

E-mail: edadueva@yandex.ru 